\title{
How we handled COVID crisis? Experience of an Indian tertiary level NICU
}

\author{
Harkirat Kaur ${ }^{1}$, Anita Singh ${ }^{2}$, Kirti Naranje ${ }^{3}$ \\ From ${ }^{1}$ Senior Resident, ${ }^{2}$ Associate Professor, ${ }^{3}$ Additional Professor, Department of Neonatology, SGPGIMS, Lucknow, Uttar Pradesh, India
}

\begin{abstract}
Background: Coronavirus disease (COVID-19) has imposed several challenges in clinical care. With rapid increase in the disease, there has been lot of incidences of COVID-19 positive exposure among the healthcare workers resulting in major crisis. Aim: The aim of the study was to emphasize various methods that can be used to manage COVID-19 crisis due to accidental exposure. Methods: An unprecedented exposure occurred to a COVID-19 positive healthcare worker in the Neonatal Intensive Care Unit (NICU), which led to quarantine of almost $90 \%$ of the primary staff. The methods undertaken included communication and continuation of clinical care through teleconsultation (video calling, zoom meetings for clinical decision, telecharting of daily prescription, and facilitating manpower from allied departments [only one pediatric resident each day], and restoration of services with come back). Results: There were total 11 babies at the time of exposure. Two babies were on respiratory support. The parents were counseled through teleconsultation. Nine babies could be discharged during quarantine period and there was no significant deterioration in the clinical condition of the two babies on respiratory support. All the babies were tested for COVID-19 as per post-exposure protocol and remained negative. Conclusion: With the help of teleconsultation and support from allied specialties and other health facilities, the crisis of COVID-19 exposure can be handled well.
\end{abstract}

Key words: COVID-19 crisis, Healthcare worker, NICU

$\mathrm{I}$ December 2019, a novel coronavirus not antecedently seen in humans was reported first in China and has currently unfolded to entire globe with more than $22,16,48,869$ confirmed cases and 4,5,82,338 fatalities [1]. The COVID-19 situation in India is severe. With a total of $33,139,981$ cases and 4,41,782 deaths, India ranks second in causative to the global burden of the disease [2]. Extensive community transmission has prompted national healthcare authorities to move from containment to a mitigation strategy.

Among adults, there have been consistent reports of scarcity of resources including beds in the Intensive Care Unit (ICU), manpower, ventilators, medicine, and personal protective equipments. This has led to necessary prioritization and triage of patients based on risk factors. In neonates, there are reports of cases of intrauterine or transplacental (vertical) transmission of SARS-CoV-2 [3].

At the institutional level, we at our institute rose to the enormity of the adversity as one united taskforce with establishment of a dedicated COVID-19 unit while maintaining continuity of service in the non-COVID-19 areas. The department of neonatology responded in conformity and dedicated itself to selfless patient

\section{Access this article online}

Received - 11 August 2021

Initial Review - 27 August 2021

Accepted - 18 September 2021

DOI: $10.32677 / \mathrm{IJCH} .2021 . v 08.110 .3064$ care. We handled this challenge by publishing our own guidelines for neonatal COVID-19 infection with the assistance of available resources [4]. Other measures which helped us streamline management during this period included: Active reinforcement of personal protective measures, adherence to social distancing in the Neonatal Intensive Care Unit (NICU), regular sanitization drives, use of telemedicine and virtual communication platforms, rapid innovations, new levels of team work and cooperation, staggering of residents and faculty on duty, maintaining continuity of academics, and weekly updating knowledge pertaining to COVID-19 in neonates and infants.

However, the department faced a major setback in continuity of patient care and academics when one of our doctors tested positive and the $90 \%$ of department including nursing staff had to be quarantined. Various methods were undertaken to handle the crisis over 2 week's period which are described below:

1. Communicating during COVID-19 crisis: The "telemedicine" way: Means of communicating for daily counseling sessions with family members were changed. Audio and video conferencing modes on phone were preponderantly used. Resident doctors from other sister departments of the institute collaborated closely to make sure patient's families got accurate and updated information about the infant's clinical status. The hospital nursing staff acted as a bridge that helped

Correspondence to: Dr. Anita Singh, Department of Neonatology, SGPGIMS, Lucknow, Uttar Pradesh, India. E-mail: dranitasinghk@gmail.com

(C) 2021 Creative Commons Attribution-NonCommercial 4.0 International License (CC BY-NC-ND 4.0). 
the quarantined and on-floor residents, and the families stay connected to each other throughout the hospital stay of the non-referable critical neonates.

Patients discharged prematurely from the hospital were followed up through telemedicine to ensure continuity of care and for further counseling. Video calls were arranged. If a parent/family member was unable to access the platform, then a telephone visit was scheduled. Encouraging observations of our process implementation included a $100 \%$ show rate for video sessions, increased access to patients, attenuated time and travel burden for patients, and increased use of synchronous video visits as users became more familiar.

For outpatients, telemedicine through a landline extension number provided prevention and treatment guidance, training, communication, and remote consulting for the community residents and medical staff. The telemedicine platform also included a departmental smartphone facility through which relevant case histories, referrals, investigations, and videos could be shared to the resident on floor. WhatsApp groups were formed to facilitate the communication at different level.
Telemedicine is a reliable information platform that delineates information regarding the ever-changing COVID-19 status, allowing medical staff to obtain and spread reliable information in real time with appropriate authentication. In addition, medical staff can communicate with colleagues, listen to lectures, apply for consultations, etc.

2. Role of residents from other departments: Resident doctors from other sister departments of the institute (Pediatric gastroenterology, Gastrosurgery, Medical Genetics, Anesthesiology, and Obstetrics) were assigned the role of patient management in view of physical non-availability of neonatology residents. Online classes and clinical rounds through various platforms were organized at regular intervals. One virtual neonatology resident and senior faculty member were made available to these residents $24 \times 7$ for various queries related to patient management. Trouble shooting was done through text messages, chats, images, video calls, and sharing of vital information surrounding neonatal care including guidelines, protocols, drug dosages, and contact numbers of residents of other departments for multidisciplinary care. Printed treatment charts were made available bedside.

Table 1: Details of the patients managed during the COVID crisis

\begin{tabular}{|c|c|c|c|c|c|}
\hline Patient No. & Gestational age (weeks) & Birth weight (grams) & Diagnosis & Outcome & Follow-up \\
\hline Patient 1 & 35 & $1800 \mathrm{~g}$ & $\begin{array}{l}\text { Type } 1 \text { Spinal muscular atrophy/Meningitis/ } \\
\text { Intracranial Bleed }\end{array}$ & $\begin{array}{l}\text { Recovered from } \\
\text { meningitis, later } \\
\text { readmitted }\end{array}$ & Healthy \\
\hline Patient 2 & 29 & $1076 \mathrm{~g}$ & $\begin{array}{l}\text { Respiratory Distress Syndrome/Late onset } \\
\text { sepsis/ NEC stage II/Apnea of prematurity/ } \\
\text { Anemia }\end{array}$ & Recovered & $\begin{array}{l}\text { Healthy and } \\
\text { thriving }\end{array}$ \\
\hline Patient 3 & $29+1$ & $1465 \mathrm{~g}$ & $\begin{array}{l}\text { Respiratory Distress Syndrome /Culture } \\
\text { positive sepsis /Pneumothorax/ Extrauterine } \\
\text { Growth Restriction }\end{array}$ & Recovered & $\begin{array}{l}\text { Healthy and } \\
\text { thriving }\end{array}$ \\
\hline Patient 4 & 37 & $2200 \mathrm{~g}$ & Neonatal cholestasis/Meningitis/UTI & Recovered & $\begin{array}{l}\text { Healthy and } \\
\text { thriving }\end{array}$ \\
\hline Patient 5 & $32+6$ & $1600 \mathrm{~g}$ & $\begin{array}{l}\text { Rh non iso-immunized/Neonatal } \\
\text { Hyperbilirubinemia/Reversed end diastolic } \\
\text { flow in umbilical Doppler }\end{array}$ & Recovered & $\begin{array}{l}\text { Healthy and } \\
\text { thriving }\end{array}$ \\
\hline Patient 6 & 38 & $3125 \mathrm{~g}$ & Neonatal Hyperbilirubinemia & Recovered & $\begin{array}{l}\text { Healthy and } \\
\text { thriving }\end{array}$ \\
\hline Patient 7 & 37 & 2700 & Meningitis/UTI & Recovered & $\begin{array}{l}\text { Healthy and } \\
\text { thriving }\end{array}$ \\
\hline Patient 8 & 38 & $2600 \mathrm{~g}$ & $\begin{array}{l}\text { Meconium aspiration syndrome/ Early onset } \\
\text { sepsis/Ventilator associated pneumonia/ } \\
\text { Severe thrombocytopenia }\end{array}$ & $\begin{array}{l}\text { Received } \\
\text { Tailored } \\
\text { care during } \\
\text { quarantine, later } \\
\text { Left Against } \\
\text { Medical Advice }\end{array}$ & Expired \\
\hline Patient 9 & 37 & $3080 \mathrm{~g}$ & $\begin{array}{l}\text { Left Renal Agenesis/Right sided } \\
\text { Hydronephrosis/Chronic Kidney Disease/ } \\
\text { Peritonitis/ Pyoperitoneum/Chronic } \\
\text { intermittent peritoneal dialysis/ Hypertensive } \\
\text { Cardiomyopathy /Developmental delay }\end{array}$ & $\begin{array}{l}\text { Received } \\
\text { Tailored } \\
\text { care during } \\
\text { quarantine, later } \\
\text { Left Against } \\
\text { Medical Advice }\end{array}$ & Expired \\
\hline Patient 10 & 37 & $2700 \mathrm{~g}$ & Neonatal Hyperbilirubinemia & Recovered & $\begin{array}{l}\text { Healthy and } \\
\text { thriving }\end{array}$ \\
\hline Patient 11 & 36 & $2480 \mathrm{~g}$ & $\begin{array}{l}\text { Rh non iso-immunized/Neonatal } \\
\text { Hyperbilirubinemia }\end{array}$ & Recovered & $\begin{array}{l}\text { Healthy and } \\
\text { thriving }\end{array}$ \\
\hline
\end{tabular}


3. Off floor but on vigil: Role of the quarantined residents: The quarantined residents responded by being available online and on call $24 \times 7$ right away. Online classes, clinical rounds, and counseling sessions were conducted in an effortless manner. Emotional, physical, and professional grievances of the on-duty residents were heard and redressed in consultation with senior faculties. Meticulous follow-up of the prematurely discharged neonates was ensured.

4. Administrative support: Senior administrators explored and opened newer avenues for patient care. From organizing and ensuring availability of residents and nursing staff from other departments to redressal of their professional and personal grievances, they delivered exemplary lessons in establishing new levels of teamwork and inter-departmental synchronization.

The outcome of the patient during the crisis is shown in Table 1. There were total 11 babies who had high risk exposure. Two babies were on respiratory support. The continuing concerns for the rest were thermoregulation, gavage feeding, continuation of antibiotics, and hyperbilirubinemia. Within 5 days of quarantine, nine babies were either discharged or shifted to other health-care facility and all were ultimately discharged to home. After 14 days of quarantine when services were restored, there was no significant deterioration in the clinical condition of the two babies on respiratory support. All the babies were tested for COVID-19 as per post-exposure protocol and remained negative.

The overall healthcare and neonatal care including the perinatal counseling have been affected a lot with COVID-19. Moreover, it is difficult to implement family cantered care in Neonatal ICUs $[5,6]$.

COVID-19 has also an impact on psychological wellbeing and academic learning and skills of health-care professionals worldwide [7]. Centers for disease control and prevention have also given recommendation for maintaining healthcare services during COVID-19 which include staggering of workforce, maintaining adequate supplies, teleconsultation, and others [8].
At our institution, the COVID-19 pandemic has altered the way our hospitals, residency program, and individual life's function. Nonetheless, we have witnessed hospital wards being converted into ICUs, rationing of masks and other personal protective equipment, shortages of high-flow oxygen machines, and restructuring of entire staffing models at both the faculty and resident levels.

As the pandemic continues to reign, it is making clear that people around the world are surprisingly alike. No matter what divides us, gratitude for health-care personnel for their gigantic work is one thing we all have in common.

\section{REFERENCES}

1. WHO Coronavirus Disease (COVID-19) Dashboard; 2021. Available from: https://www.covid19.who.int [Last accessed on 2021 Sep 09].

2. Coronavirus Outbreak in India; 2021. Available from: https://www. covid19india.org [Last accessed on 2021 Sep 09].

3. Vardhelli V, Pandita A, Pillai A, Badatya SK. Perinatal COVID-19: Review of current evidence and practical approach towards prevention and management. Eur J Pediatr 2021;180:1009-31.

4. Naranje KM, Gupta G, Bajpai S, Verma A, Jaiswal R, Pandey A, et al. Neonatal COVID-19 infection management. J Neonatol 2020;34:88-98.

5. Kostenzer J, Hoffmann J, von Rosenstiel-Pulver C, Walsh A, Zimmermann LJI, Mader S, et al. Neonatal care during the COVID-19 pandemic-a global survey of parents' experiences regarding infant and family-centred developmental care. EClinicalMedicine 2021;39:101056.

6. Litmanovitz I, Silberstein D, Butler S, Vittner D. Care of hospitalized infants and their families during the COVID-19 pandemic: An international survey. J Perinatol 2021;41:981-7.

7. Giannis D, Geropoulos G, Matenoglou E, Moris D. Impact of Coronavirus disease 2019 on healthcare workers: Beyond the risk of exposure. Postgrad Med J 2021;97:326-8.

8. Maintaining Essential Health Services during COVID-19 in Low Resource, Non-U.S. Settings; 2021. Available from: https://www.cdc.gov/ coronavirus/2019-ncov/global-covid-19/essential-health-services.html [Last accessed on 2021 Sep 09].

Funding: None; Conflicts of Interest: None Stated.

How to cite this article: Kaur H, Singh A, Naranje K. How We Handled COVID Crisis? Experience of an Indian Tertiary Level NICU. Indian J Child Health. 2021; 8(10):377-379. 